\title{
The International Competitiveness of Computer and Information Service Trade between China and India
}

\author{
Saifang Wang \\ Economics School of Shenzhen Polytechnic \\ Shenzhen, China \\ saifangwang@szpt.edu.cn
}

\begin{abstract}
Based on the statistics published in UNCTAD, this paper measures the international competitiveness of computer and information service trade between China and India by using the four analytic tools such as TC, IMS, RCA, and NEPR Indicators. The results show that there are huge differences between the two countries as far as the international competitiveness of this industry is concerned. Suggestions are given at the end of this paper that the Chinese governments give priorities to developing computer and information industry by offering more policy supports and cultivating more related talents so that the international competitiveness of this industry can be consistently enhanced.
\end{abstract}

Keywords-computer and information service industry; international competitiveness; revealed comparative advantage

\section{INTRODUCTION}

"The Creative Economy: 2010 Report" defined computer and information services as "covers computer data and news-related service transactions between residents and non-residents". Computer and information service industry include seven areas of services. For instance, "databases, such as development, storage, and online time series;" data processing, "management of facilities of others on a continuing basis; hardware consultancy; software implementation — including design, development, and programming of customized systems; maintenance and repair of computers and peripheral equipment; news agency services - including provision of news, photographs, and feature articles to the media; and direct, non-bulk subscriptions to newspapers and periodicals[1]."

The reason why the author chooses Indian as an object to compare with is that the export of this industry in India has been ranked as world No. 1 consecutively in the past 10 years and is still developing in a rapid way. Statistics published by UNCTAD shows that in 2002 the export of computer and information service trade of India is 8,889 millions of dollars; in 2008 it reaches as high as 49,379 millions of dollars with a growth rate of $46 \%$. By contrast, in 2002 , the export of computer and information service trade in China is just 638 millions of dollars. Though from that on, the export of computer and information service trade of China achieves a stable growth and reaches 6,252 millions of dollars in 2008 which is 10 times as that in 2002. However, this number is far below the export of India in 2002. China and India are both developing countries with a huge amount of population, and are also famous with their respectively brilliant civilizations. But compared with China, India has achieved its great success on computer and information service trade. India's experience in this technology intensive field is undoubtedly worth learning.

The huge success of India in computer and information service has attracted the attention of Chinese scholars. Chen, Zhang, and Yang(2006) [2] analyzed the reasons why India could achieve its international comparative advantages in computer and information service trade industry. They used Michael Porter's Diamond model as a framework to figure out the reasons from 6 aspects such as factors endowments, domestic demand, the related and supporting industries, firm strategy, structure and rivalry, government support and chance. Lan (2008) [3] studied the sources of competitiveness of the software industry in India from the perspective of industry cluster. He argues that the software industry in India possesses its positive market competitiveness due to the learning effect resulted from the interior of the industry cluster as well as the capability to take advantage of regional resources. Nie and Dong (2008) [4] use descriptive Indicator, TC Indicator and RCA Indicator to analyze the status quo of the computer and information service trade between China and India. But the analytic tools used in their paper are not comprehensive enough and the statistics they used is outdated. Zhao and Hang (2009) [5] compared China with some other countries in the field of computer and information service, but not exclusively compared China with India in this field.

In conclusion, although some Chinese scholars have studied the development and international competitiveness of computer and information service trade industry, they focus on this subject mainly from the perspective of Michael Porter's "Diamond Model", and few studies can be found in the literature which are solely dealt with the comparative studies on the competitiveness of computer and information service industry in a comprehensive way. Therefore, based on the previous studies in this field, and the statistics published by UNCTAD, this paper makes a quantitative and comparative study on the international competitiveness of computer and information service trade industry between China and India. 
II. MEASURE OF THE INTERNATIONAL COMPETITIVENESS OF COMPUTER AND INFORMATION SERVICE TRADE INDUSTRY BETWEEN CHINA AND INDIA

The UNCTAD Creative Economy Database published the statistics on the import and export of computer and information service trade. Based on this database and other resources, this paper selects TC Indicator, IMS Indicator, RCA Indicator, and NEPR Indicator to measure the international competitiveness of the computer and information service trade industry between China and India.

\section{A. TC Indicator}

The TC Indicator ("Trade Competition Indicator" in short) is a commonly used indicator to analyze international trade competitiveness. It refers to the ratio of the import or export of a product or service in a country or an area to its total import and export volume.

$$
\mathrm{TC}_{\mathrm{ij}}=\left(X_{i j}-M_{i j}\right) /\left(X_{i j}+M_{i j}\right)
$$

In formula (1), $X i j$ refers to the export volume of $j$ product or service in country or area $i$; Mij stands for the

TARIE 1.
\begin{tabular}{|r|l|l|l|l|l|l|l|}
\hline Year & $\mathbf{2 0 0 2}$ & $\mathbf{2 0 0 3}$ & $\mathbf{2 0 0 4}$ & $\mathbf{2 0 0 5}$ & $\mathbf{2 0 0 6}$ & $\mathbf{2 0 0 7}$ & $\mathbf{2 0 0 8}$ \\
\hline Comntry & & & & & & & \\
\hline China & -0.28 & 0.03 & 0.13 & 0.06 & 0.26 & 0.33 & 0.33 \\
\hline India & 0.82 & 0.89 & 0.89 & 0.89 & 0.87 & 0.83 & 0.87 \\
\hline
\end{tabular}
Source: Calculated based on statistics from UNCTAD

import volume of $j$ product or service in country or area $i$. Because TC Indicator gets rid of the influences of currency inflation and economy inflation, it is comparable between different periods and different countries. When $\mathrm{TC}=1$, it means that this product or service only exports, and it does not imports. The closer TC gets to 1 , the greater its competitiveness. If $\mathrm{TC}=-1$, it shows that this product or service only imports. It does not export at all. When TC gets closer to -1 , it indicates that the competitiveness is becoming weaker.

Figure 1 shows that the TC Indicator of the computer and information service trade in China in 2002 was smaller than

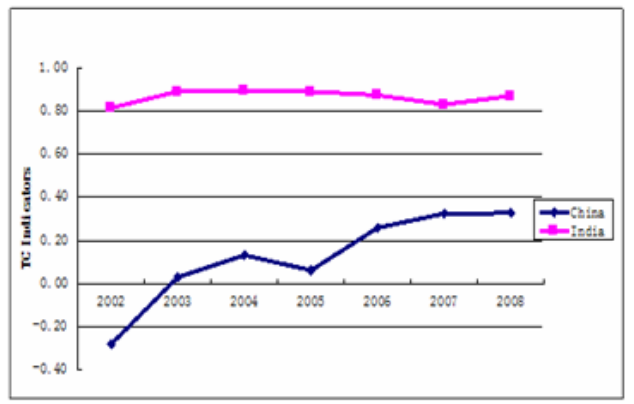

Figure 1. TC Indicators of computer and information service of China and India (2002-2008)

Source: Calculated based on statistics from UNCTAD

0, but from 2003 on, it was bigger than 0 , and it grew fast in 2004. But in 2005, it dropped to the level in 2003. The TC
Indicator began to rise significantly in 2006, till it maintained the same level in 2007 and 2008. Figure 1 indicates that there is a rising trend in the international trade competitiveness as a whole in China in this field. From 2002 to 2008, the TC Indicators of the computer and information service trade has been consecutively bigger than 0 , and closer to 1 . It shows that India has very strong international competitiveness in this industry.

\section{B. IMS Indicator}

The International Market Share Indicator (IMS Indicator) represents the ratio of the export volume of a product or service in a country or an area to the total export volume of this product or service in the whole world. It shows the overall competitiveness of export of a certain product or service in a country or an area.

$$
I M S_{i j}=\frac{X_{i}}{X_{\text {wi }}}
$$

In (2), $I M S_{i j}$ refers to the international market share of the product or service $j$ in country or area $j . \quad X_{*}$ refers to the total export volume of $j$ in $i ; X_{w j}$ stands for the total export volume of $j$ in the world. The variation of IMS reflects the change of the international competitiveness and comparative status of a certain industry or product in a country. The bigger the value of IMS Indicator shows the stronger the

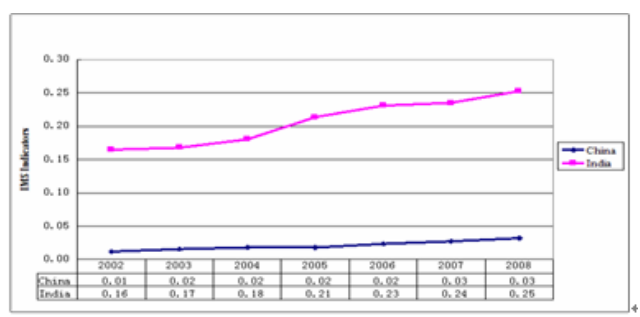

Figure 2. MMS Indicators of computer and information service of China and India (2002-2008)

Source: Calculated based on statistics from UNCTAD

international competitiveness of this product or service while an improvement of this ratio suggests a rising competitiveness of export.

The development of computer and information service trade of India takes a leading position in the world from the very start. Figure 2 shows that its IMS maintains above 15 percent, and is rising steadily. By contrast, the IMS in China is far below that in Indian by 10 to 20 percent, and has been growing slowly. It suggests that the international competitiveness of computer and information service trade is comparatively weak but with a slow and rising trend.

\section{RCA Indicator}

The Revealed Comparative Advantage Indicator (NEPR Indicator) is a powerful tool to measure the competitiveness of a certain industry or product in a country or an area. It refers to the ratio between the proportion of the export volume of a certain product or service in a country or an area 
among its total export and the proportion of the world export of this product or service among the world total export.

$$
R C A_{i j}=\left(X_{i j} / X_{t j}\right) /\left(X_{i w} / X_{t w}\right)
$$

RCAij stands for the revealed comparative advantage of the product or service $i$ in country or area $j$. Xij represents the export of product or service $i$ in country or area $j ; X t j$ means the total export of country or area $\mathrm{j}$ in t period; Xiw shows the total export of product or service $i$ in the world market; $X t w$ means the world total export in $t$ period. Generally speaking, if $R C A_{i j}>2.5$, it means this product or service has very strong international competitiveness; if $1.25 \leqslant$ $R C A_{i j} \leqslant 2.5$, it means that this product or service has comparatively strong international competitiveness; if $0.8 \leqslant$ $R C A_{i j} \leqslant 1.25$, it means medium level competitiveness; if $R C A_{i j}<0.8$, it shows a relatively low competitiveness of this product of service.

Table 2 indicates that the RCA of the computer and

\begin{tabular}{|c|c|c|c|c|c|}
\hline 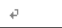 & 2004 & 2005 & 2006 & 2007 & 2008 \\
\hline China & 0.25 & 0.23 & 0.27 & 0.28 & 0.33 \\
\hline India & 14.91 & 15.03 & 15.07 & 13.11 & 13.42 \\
\hline
\end{tabular}

information service trade in China is far below 0.8 from the very beginning, showing that as a whole, this industry in China is inadequate in comparative advantage and its international competitiveness is rather weak. But from 2005, the RCA of computer and information service trade in China shows a slow rising trend. On the other hand, the RCA in India has been above 13. It shows very clearly that India has very strong international comparative advantage in computer and information service trade, though the RCA drops in 2007, showing its comparative advantage declines slightly.

\section{NEPR Indicator}

The Net Export Performance Ratio (NEPR Indicator) represents the ratio between the proportion of the pure export of a certain product or service in a country of an area and the proportion of this product or service among the total volume of the world trade. The formula to calculate NEPR is:

$$
N E P R=\left[\left(X_{i j}-M_{i j}\right) / X_{t j}\right] /\left(X_{i w} / X_{t w}\right)
$$

In (4), $X_{i j}$ stands for the export volume of the product or service $i$ in country or area $j ; M_{i j}$ means the import volume of $i ; X_{i j}$ refers to the total export of $j$ in $t$ period; $X_{i w}$ is the total export amount of the world market in $t$ period. Generally speaking, if NEPR $>1$, then this industry has relatively strong comparatively advantage; if $0<\mathrm{NEPR}<1$, then this industry has certain comparative advantage; if NEPR $<0$, it shows that this product or service has low or no comparative advantage. From figure 3, we can

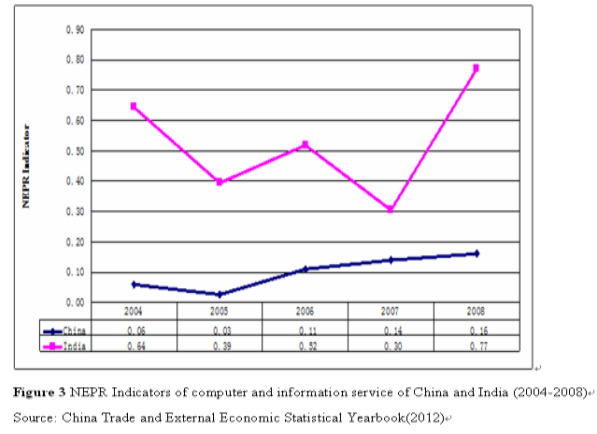

find that the NEPR from 2004 to 2008 in India computer and information service trade is bigger than that in China, which shows that compared with China, India is more comparative in the field of computer and information service trade while the NEPR in China is very small between 2004 and 2005. But it starts to rise from 2006 although at a very slow rate.

\section{III.CONCLUSION AND IMPLICATIONS}

The above passages discuss the measurement of international competitiveness between China and India in the field of computer and information service trade by means of 4 analytic tools such as TC Indicator, IMS Indicator, RCA Indicator and NEPR Indicator. So far, a conclusion can be drawn: there is huge gap between China and India in the international competitiveness of computer and information service trade. Compared with India, China is still inadequate in comparative advantage and international

TABLE 3 THE STATUS-QUO OF THE INTERNATIONAL COMPETITIVENESS OF COMPUTER AND INFORMATION SERVICE IN CHINA AND INDIA (2002-2008)

\begin{tabular}{|l|l|l|l|l|}
\hline \multirow{2}{*}{ Country } & \multicolumn{2}{|c|}{ China } & \multicolumn{2}{c|}{ India } \\
\cline { 2 - 5 } & competitiveness & Development trend & competitiveness & Development trend \\
\hline TC & Weak & huge rise after 2005 & Strong & small range of decrease in 2006, but rise in 2008 \\
\hline IMS & Weak & Steady increase & Strong & huge and steady increase \\
\hline RCA & Weak & steady but slow increase & Strong & big drop in 2007, but rise in 2008 \\
\hline NEPR & Weak & huge increase from 2005 & Strong & $\begin{array}{l}\text { Big drop between 2005 and 2007, but rapid } \\
\text { increase in 2008 }\end{array}$ \\
\hline
\end{tabular}

competitiveness in computer and information service trade industry. But from the perspective of the development trend of this industry of China, especially from 2005, the value of three indicators out of the four listed above is steadily or rapidly increasing. It means that the gap is narrowing. The conclusion shows that on one hand, the international competitiveness of computer and information service trade in China is greatly lagging behind India, but on the other hand, China is making progress, though, the progress is not satisfactory. Measures could be taken in the following aspect to improve the international competitiveness in the industry of computer and information service trade in China. 
The government level

The Chinese government could help a lot by encouraging innovation and by protecting intellectual property. On one hand, the government could stimulate software R\&D enterprises to make innovations by offering them lowinterest rate of loans and reducing taxes so as to cut their operation cost. On the other hand, the government should take strict measures to protect intellectual property. Although the government has achieved great success in fighting against pirated software, further needs to be done to protect intellectual property.

The education level

Education and training of IT talents and entrepreneurs is a very urgent task in China. India has established its mature multi-level talents in the computer and information service. In this pyramid structure, the $R \& D$ engineers and top level management teams are located on the top, with the system analysts in the middle. On the bottom of the pyramid sit "software blue collars", such as software designers and programmers. This provides continuous human resource to the computer and information service industry. But the case in China is that we lack the top level engineers and the bottom level blue collars. Thus, the way out is to establish feasible talent structure.

The industry level
The computer and information service industry should establish its industry cluster. Industry clusters can offer companies scale economy to reduce their production cost and risk in research and development of software.

\section{REFERENCE}

[1] Creative Economy: $2010 \quad$ Report. http://www.doc88.com/p-99193307560.html

[2] Chen,Hua-chao, Zhang, Yu-ke and Yang, Hong-ling. Analysis on the International Competitive Power of India's Software Industry From the Theory of the Competitive Advantage. Journal of Hebei University (Philosophy and Social Science). Vol. 3, (2006)

[3] Lan, Qin-xin. The Inner Economy Effect of Industrial Cluster from Software Industry Development in India. Asia-pacific Economic Review. Vol.5, (2008)

[4] Nie, Hong and Deng, Jin. A Comparative Study of the International Trade Competitiveness in Computer and Information Services between China and India. Journal of Beijing Institute of Technology(Social Sciences Edition). Vol. 4, (2008).

[5] Zhao, Shu-hua and Han, Fei. An International Comparison of Competitiveness on China Computer and Information Service Trade Based on a Comparative Study of Competitiveness Indicators. The Economy Forum, Vol, 3, (2009).

[6] China Trade and External Economic Statistical Yearbook(2012), China Statistics. 